\title{
The Influence of Chronotype and Grit on Lifestyle and Physical Activity
}

\author{
Melody F. Allee \\ Sarah E. Anderson \\ Myra J. Bloom, M.A., M.L.I.S. \\ Scarlet R. Jost, M.S. \\ Donald P. Keating III \\ Andrew S.I.D. Lang, Ph.D. \\ Nancy V. Mankin, M.Ed. \\ Zachary W. Mast \\ Philip P. Nelson, Ph.D. \\ Esther M. Spear \\ Enrique F. Valderrama, Ph.D. \\ Oral Roberts University
}

\begin{abstract}
Background: The chronotype of a person refers to an individual's natural sleep-wake cycle and whether that individual prefers morning or evening activities, and grit is an individual's perseverance and passion for long-term goals.

Aim: The purpose of this study was to investigate the relationship between grit, chronotype, physical activity, and leading a healthy lifestyle in college-age students.

Methods: Health and fitness data (i.e., chronotype, grit, lifestyle assessment score, and daily steps) from 431 first-semester university students at a private college were collected and analyzed.

Results: This study found that grit and chronotype both have significant correlations with living a healthy lifestyle and with physical activity. Grit more accurately predicts a person's lifestyle $(\beta=-13.712, \mathrm{r}=0.39$, $p<0.0001)$ while chronotype more accurately predicts the physical activity, or steps, of a person $(\beta=$ $66.48, r=.19, p=.0001)$. Chronotype can also accurately predict the grit of a person $(r=.25, p<.0001)$, and it was found that morning people tend to have more grit.

Conclusions: This study concluded that grit, chronotype, steps, and a healthy lifestyle are all significantly correlated with each other. Knowing the relationship between endogenous chronotype, grit, and living a physically active and healthy lifestyle can help inform policy decisions related to the goal of strengthening an institution's inclusive and healthy academic community.
\end{abstract}

Submitted 14 April 2020: accepted 29 July 2020

Keywords: chronotype, college students, grit, healthy lifestyle, MEQ, physically active lifestyle, steps

Chronotype refers to a person's natural disposition with regard to their sleep-wake cycle and their preference for morning or evening activities (Horne \& Östberg, 1976). Morning chronotypes (larks) have an easier time waking up 
in the morning and are more alert and energetic during the morning hours. Whereas evening chronotypes (owls) prefer to sleep in and are more alert and energetic later on in the day and into the evening. Chronotype, typically measured on a scale from 16 to 86 (Horne \& Östberg, 1976), varies significantly by gender and age with men typically having a later chronotype than women and with adolescents typically having the latest chronotypes in both sexes, reaching a peak in lateness at 18.4 years old in females and 19.2 years old in males and slowly declining thereafter (Fischer, Lombardi, Marucci-Wellman, \& Roenneberg, 2017).

Chronotype has been found to influence academic performance and mental health. College age students who align class times with chronotype can significantly improve academic performance with morning chronotypes performing best in morning classes and evening chronotypes performing best in evening classes (Ferguson et al., 2018; Goldin, Sigman, Braier, Golombek, \& Leone, 2020). Morning chronotypes spend more time reading and engaging in physical activity, while evening chronotypes spend more time on screens. However, evening chronotypes spend more time with their friends than morning chronotypes (Kauderer \& Randler, 2013). College students typically have poor sleep hygiene, which has been linked to increased anxiety and perceived academic stress, which in turn has been associated with depression; this cycle is exacerbated for evening chronotypes (Romo-Nava et al., 2016; Dickinson, Wolkow, Rajaratnam, \& Drummond, 2018; Park, Lee, \& Lee, 2018; Norbury \& Evans, 2019).

Evening chronotypes typically lead less healthy lifestyles than their morning counterparts; in general, they are less physically active, make less healthy food choices (especially at night), and are more likely to drink and smoke (Schaal, Peter, \& Randler, 2011; Urbán, Magyaródi, \& Rigó, 2011; Haraszti et al., 2014; Maukonen et al., 2016; Mota et al., 2016). These chronotype-related behaviors are associated with metabolic syndrome, obesity, insulin resistance, and elevated blood pressure (Vera et al., 2018; McMahon et al., 2019) that in the long term often lead to a poor healthrelated quality of life (Suh et al., 2017). In fact, sufficient evidence now exists across a wide variety of cultures and age groups to conclude that, on average, late chronotypes experience worse general mental and physical well-being than early chronotypes (Bullock, 2019). This conclusion is significant for colleges and universities whose incoming freshmen are about to reach their peak "lateness" as measured by their mid-point of sleep (Fischer et al., 2017).

Grit is commonly defined as a perseverance and passion for long-term goals (Duckworth, Peterson, Matthews, \& Kelly, 2007). Grit has been correlated with student retention (Saunders-Scott, Braley, \& Stennes-Spidahl, 2018), but perseverance was found to be most useful for predicting success (Crede, Tynan, \& Harms, 2017). Grit is also associated with various well-being outcomes, such as, psychological well-being (Salles, Cohen, \& Mueller, 2014), behavioral engagement, emotional engagement, flourishing (Datu, Valdez, \& King, 2016), enhanced purpose in life (Kleiman, Adams, Kashdan, \& Riskind, 2013; Hill, Burrow, \& Bronk, 2016), and lower levels of depression and anxiety (Musumari et al., 2018). Grit may be particularly useful for those who have resolved their identities and identified with their commitments (Weisskirch, 2019). Individuals who believe that life is meaningful and purposeful tend to maintain perseverance and passion in order to achieve their long-term goals (i.e., have higher levels of grit), and in turn are likely to have lower levels of depression and anxiety. These findings are especially important for university students as they are in the midst of establishing their self-identities and at higher risk for developing mental health problems (Kroger, 2005; Pedrelli, Nyer, Yeung, Zulauf, \& Wilens, 2015).

Maintaining a physically active lifestyle is one of the most important things a person can do for themselves (Warburton \& Bredin, 2017). Agencies, such as the Centers for Disease Control and Prevention (CDC) and the World Health Organization (WHO) advise for a certain frequency and duration of moderate-to-vigorous physical activity in order to reap the greatest health benefits (CDC, 2020; WHO 2020, Tudor-Locke \& Aguiar, 2018). 
Regular physical activity can reduce the risk of depression and anxiety, strengthen bones and muscles, help you sleep better, and help you get to or stay at a healthy weight. Regular physical activity also helps reduce the risk of serious health issues such as cardiovascular disease, type-2 diabetes, metabolic syndrome, and even some cancers (CDC, 2020). Physical activity interventions based upon a 10,000 steps per day recommendation produce significantly lower anxiety, depression, anger, fatigue, confusion, and total mood distress scores comparatively (Yuenyongchaiwat, 2016).

College students who regularly engage in physical activity are found to have superior muscular strength, stamina, and flexibility (Cheng, Yang, Ting, Chen, \& Huang, 2011), in addition to enhanced health responsibility, stress management, nutrition, and healthy lifestyle behaviors (Türkmen, Kul, Ocalan, Özkan, \& Bozkus, 2013). Healthier lifestyle choices result in higher life satisfaction and lower psychological distress (Velten et al., 2014). A recent study analyzed data (academic performance measured by GPA, Fitbit activity data, lifestyle survey scores, and timed 1-mile field tests) from a sample of 581 first-year college students (Broaddus et al., 2019). Study results reported positive and significant correlations among Fitbit step counts, 1-mile field test times, lifestyle survey scores, and academic performance even when controlling for gender. Together, these findings highlight the importance for students to maintain a physically active and healthy lifestyle after they enter university.

The individual measures of grit, chronotype, physical activity, and healthy lifestyle behaviors have been significantly correlated with academic performance and other various aspects of a college student's general well-being; therefore, one might expect these measures to be correlated with one another. However, to date, how these various dimensions influence each other is not well understood.

The aim of the study was to quantify the relationship between grit, chronotype, physical activity, and leading a healthy lifestyle in college-age students. In particular, we wanted to examine how standard measures of grit and chronotype are related to each other, an approach that has not been used before. The relationship between grit and chronotype is important to understand as they both have significant general well-being implications and, in particular, for college students, they can affect academic performance. We also examined what, if any, associations exist between both grit and chronotype and a student's physically active and healthy lifestyle score. These relationships are important to understand as they may suggest possible student success related recommendations and interventions.

\section{METHOD}

The data in this study were collected from 431 first-semester students enrolled in a course entitled Introduction to Whole Person Education at a university located in Oklahoma during the fall 2019 semester. As part of the course's physical activity requirements, all enrolled students are required to record daily step counts, take part in a timed field test (they may either run or walk), and participate in various university success related discussions which include the measurement and meaning of both grit and chronotype. Before the course began, all students were informed of the study and given the option to "opt in." The students who opted in consented by selecting checkboxes that permitted the university to collect daily step counts automatically from Fitbit devices and sync them into the course's grade book, as well as use all other course-related survey data, demographic data, and grades. This study did not include data from the students who opted out of the study (the default option). The university's Institutional Review Board approved the study. The demographics of the participants are presented in Table 1. 
Table 1

Summary of Demographic Data Used in this Study, $\mathrm{N}=431$.

\begin{tabular}{llll}
\hline \hline & Female & Male & Total \\
\hline Variable & $\mathrm{N}$ & $\mathrm{N}$ & $\mathrm{N}$ \\
\hline Freshmen & 229 & 147 & 376 \\
Sophomore & 20 & 16 & 36 \\
Junior & 10 & 5 & 15 \\
Senior & 3 & 1 & 4 \\
Total & 262 & 169 & 431 \\
\hline
\end{tabular}

\section{Measures}

The course has a required health and physical exercise component that includes, among other things, measurement of chronotype and grit, lifestyle assessment surveys and a daily steps goal. The dataset is available as Open Data (CC0) via figshare (Lang et al., 2020). Table 2 displays the summary statistics of the data for the following variables:

Age. The age of the student, in years, on December 1, 2019 (the day the age data were imported into our student records system, one week before the course ended).

Grit. A measure of each student's "grit” using Duckworth et al.'s (2007) standard 12-question instrument. For validity, items were developed based on existing theoretical and empirical grit and persistence literature and informed by expert review. For reliability, internal consistency estimates (Cronbach's alpha) for the Grit Scale have been reported as 0.85 (Duckworth et al., 2007).

Lifestyle. A measure of how healthy a lifestyle the student is leading. Each student's lifestyle was measured using a 35-question lifestyle survey. Survey items covered aspects of personal health care, drug and alcohol use, physical fitness, psychological condition, spiritual condition, personal behavior, and nutrition (Huber, 2016). Based on the assessment scores, lifestyles were divided into five categories: 1) very healthy (<40); 2) healthy (41-70); 3) average (71-100); 4) unhealthy (101-130); and 5) very unhealthy (>131). The lifestyle survey instrument is based on several validated lifestyle surveys (see Huber, 2016 for details). Items were selected to match the institution's whole person education philosophy and student learning outcomes and informed by expert review by the institution's health and physical exercise faculty members.

MEQ. A measure of each student's chronotype (a measure of one's preference for, and effectiveness in doing, morning or evening activities) using the standard 19-item Morningness-Eveningness Questionnaire (MEQ; Horne \& Östberg, 1976). For validity, studies used the MEQ instrument in individuals without a diagnosis of circadian rhythm disorder and used objective circadian phase marker testing, which resulted in subjects with a later circadian phase scoring lower on the MEQ (Sack et al., 2007). For reliability, internal consistency estimates (Cronbach's alpha) for the MEQ scale have been reported as 0.83 (MEQ; Horne \& Östberg, 1976). 
Sex. The sex of the student was encoded as " 0 " female and " 1 " male. Data were collected from 262 females $(61 \%)$ and 169 males (39\%).

Steps. The average number of steps that study students took per day as a measure of physical activity. For all students enrolled in the course, a step count goal of 10,000 steps per day was required (Oral Roberts University, 2017). Reported step counts were part of the student's course grade. For students who opted into the study (over 95\%), daily step counts were measured using Fitbit devices and automatically synced to the course gradebook.

Table 2

Summary Statistics of the Data Used in this Study, $\mathrm{N}=431$.

\begin{tabular}{|c|c|c|c|c|c|c|c|c|c|c|c|}
\hline \multirow[b]{2}{*}{ Variable } & \multicolumn{3}{|c|}{ Female } & \multicolumn{3}{|c|}{ Male } & \multicolumn{2}{|c|}{ T-test } & \multicolumn{3}{|c|}{$\overline{\text { Total }}$} \\
\hline & $\mathrm{N}$ & Mean & SD & $\mathrm{N}$ & Mean & SD & $\mathrm{t}$ & $\mathrm{p}$ & $\mathrm{N}$ & Mean & SD \\
\hline Age & 262 & 19.2 & 2.4 & 169 & 19.3 & 2.5 & -0.6 & 0.55 & 431 & 19.3 & 2.4 \\
\hline Grit & 179 & 3.5 & 0.5 & 114 & 3.6 & 0.5 & -1.2 & 0.23 & 293 & 3.6 & 0.5 \\
\hline Lifestyle & 240 & 73.0 & 19.0 & 160 & 69.0 & 17.9 & 2.1 & $0.03 *$ & 400 & 71.4 & 18.6 \\
\hline MEQ & 236 & 47.0 & 7.6 & 147 & 48.4 & 7.6 & -1.7 & 0.08 & 383 & 47.5 & 7.6 \\
\hline Steps & 262 & 10,227 & 2,092 & 169 & 12,043 & 2,981 & -6.9 & $0.00 * * *$ & 431 & 10,939 & 2,630 \\
\hline
\end{tabular}

\section{Statistical Analysis}

The Shapiro-Wilk test was used to assess the normality of distribution for the investigated parameters. Sex differences were tested by using a two-tailed $t$-test. Pearson's correlation was used to analyze the association between all studied parameters. The values $p<.05$ were considered statistically significant. Statistical analysis was done using R v. 3.6.0 (R Core Team, 2019).

\section{RESULTS}

\section{Normality}

Using the Shapiro-Wilk test $(p>0.05$ was taken for normality), the normality of distribution for each variable was assessed, and only MEQ was found to be normally distributed $(p=.77)$.

\section{Sex Differences}

Each variable was tested to see if there was a difference in mean value for men and women by using a two-tailed ttest with significant differences $(p<0.05)$ found for lifestyle (with women leading less healthy lifestyles) and steps (with men taking an average of 1,766 more steps per day than women; Table 2 and Figure 1). 

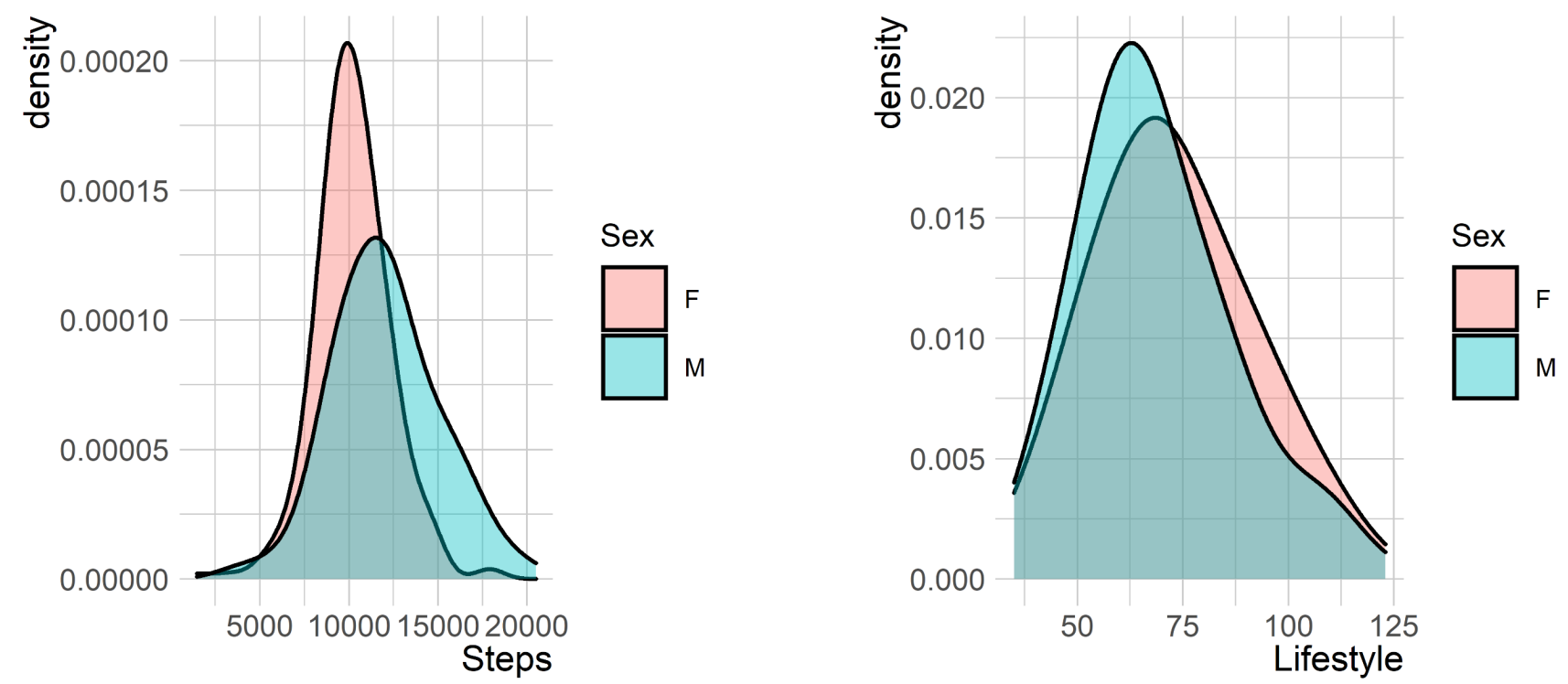

Figure 1. Steps and Lifestyle by Sex. Males have a higher and more dispersed steps per day count than females, and females have higher (less healthy) lifestyle scores than males.

\section{Correlations}

The correlation matrix (Table 3), shows significant correlations between various variables in the study. Of particular interest to our research was the significant correlations between steps and sex, age, and MEQ; and lifestyle and sex, grit, and MEQ.

Table 3

Correlation Matrix for the Study V ariables.

\begin{tabular}{llllllc}
\hline Variable & Steps & Sex & Age & Lifestyle & Grit & MEQ \\
\hline Steps & 1.00 & $0.34^{* * *}$ & $-0.19^{* * *}$ & $-0.23^{* * *}$ & 0.11 & $0.19^{* * *}$ \\
Sex & & 1.00 & 0.03 & $-0.11^{*}$ & 0.07 & 0.09 \\
Age & & 1.00 & 0.01 & 0.07 & $0.13^{*}$ \\
Lifestyle & & & 1.00 & $-0.39 * * *$ & $-0.25^{* * *}$ \\
Grit & & & & 1.00 & $0.25^{* * *}$ \\
MEQ & & & & & 1.00 \\
\hline
\end{tabular}

$* p<0.05 ; * * * p<0.001$

\section{Physically Active Lifestyle}

As noted previously, there was a significant difference in the average number of steps taken per day between men and women, with men on average taking 1,766 more steps per day than women $(r=0.34, p<.001)$. The correlation between steps and age means that on average, the older the student the less steps they average per day $(r=-.19, p<$ .001). The correlation between steps and MEQ indicates that the more of a morning person the student happens to be, the more steps they take each day $(r=.19, p<.001)$. When controlling for sex and age, the correlation between 
steps and MEQ was found to still be significant $(\beta=64.89, p<.001 ;$ Steps $=11416+1806 *$ Sex $-221 *$ Age +64.89 * MEQ). Figure 2 displays the plot of Steps against MEQ colored by age and symbolled by sex.

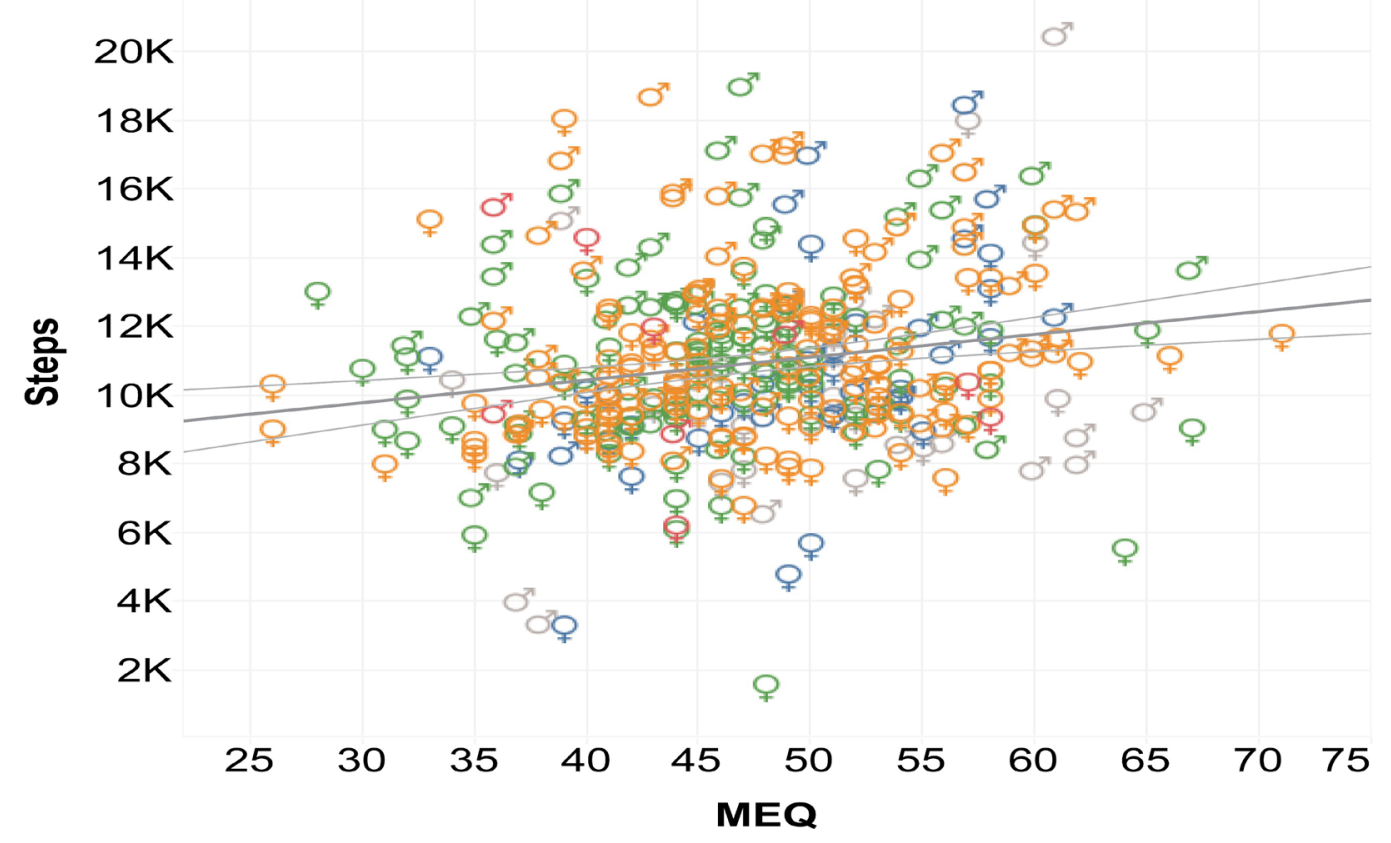

Figure 2. Steps by MEQ. The figure is colored by age (16-17 red, 18 orange, 19 green, 20-21 blue, 22+ light grey) and with symbols $(\hat{0})$ and $(+)$ indicating male and female respectively (48 MEQ null values), adjusted r-squared $0.18, p<$ .01 .

The relationship between Steps and Grit was not significant at the 0.05 level $(r=.11, p=.0615)$. However, the relations became significant once sex and age were controlled for $(\beta=509.28, p=.0496$; Steps $=13353+1661 *$ Sex - $262 *$ Age $+509.28 *$ Grit). Figure 3 displays a plot of steps against grit colored by age and symbolled by sex.

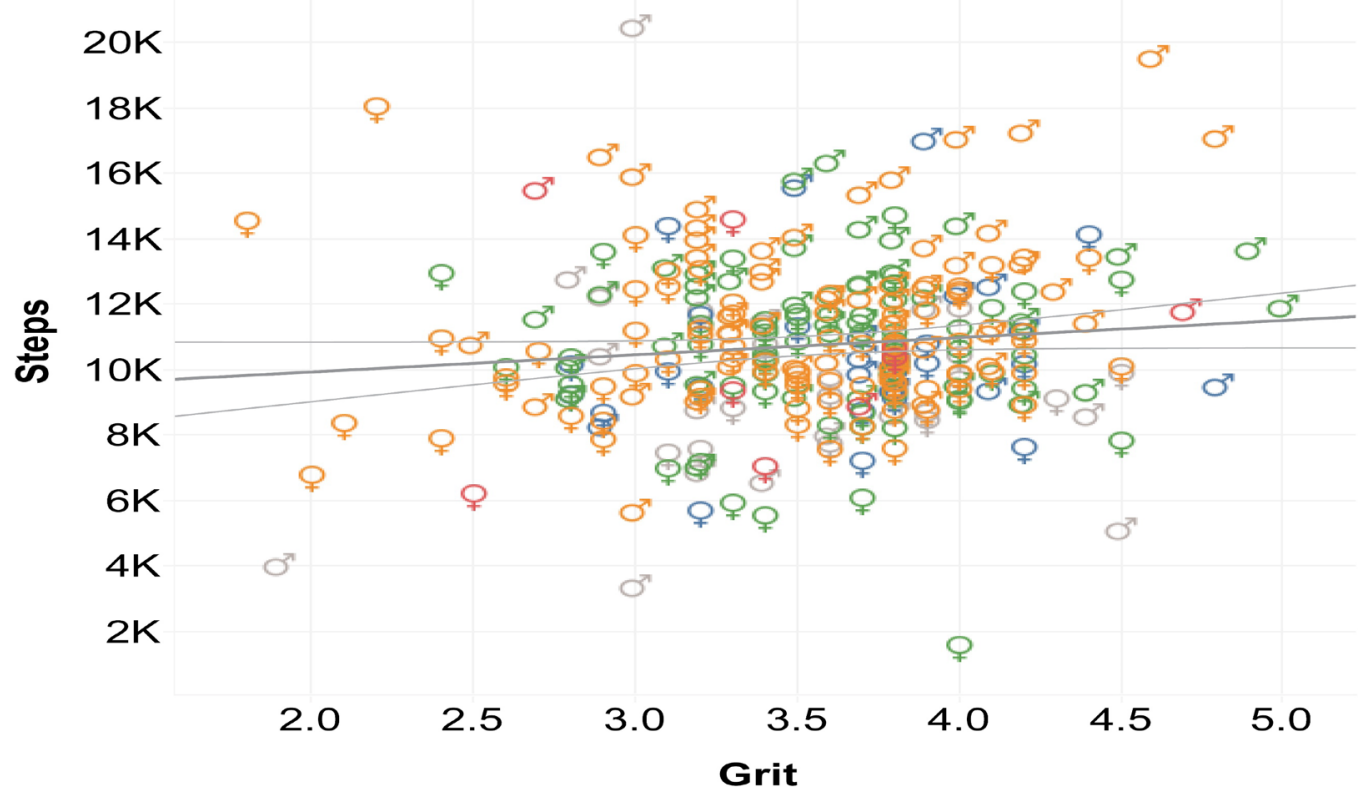

Figure 3. Steps by Grit. The figure is colored by age (16-17 red, 18 orange, 19 green, 20-21 blue, 22+ light grey) and the symbols $\left(0^{\top}\right)$ and $(+)$ indicate male and female respectively (138 Grit null values), adjusted $\mathrm{r}^{2}=.16, p<.001$. 
Finally, steps are negatively correlated with lifestyle score (the higher the score, the less healthy the lifestyle), $r=$ $-.23, p<.001$.

\section{Healthy Lifestyle}

The Lifestyle variable is a measure of how healthy a lifestyle the student is leading, with higher lifestyle scores corresponding to less healthy lifestyles. Lifestyle is negatively correlated with $\operatorname{sex}(\beta=-3.992, p=.0357$; Figure 1), with men, in general, leading a healthier lifestyle by an average of 4 points, 69 vs. 73 respectively. Lifestyle is also negatively correlated with both grit $(\beta=-13.712, p<.001)$ and MEQ $(\beta=-0.618, p<.001)$.

Creating a general linear model for Lifestyle, selected by Akaike information criterion (AIC) and an exhaustive best subsets approach, grit is found to be the overall most significant factor for predicting lifestyle (Grit $\mathrm{p}<0.0001$, MEQ $p=0.0054$, model: adjusted $\left.\mathrm{r}^{2}=.18, \mathrm{p}<.0001\right)$. Figure 4 displays the plot for predicted values versus measured values using the equation Lifestyle $=138.621-0.447 * \mathrm{MEQ}-12.917 * \mathrm{Grit}$.

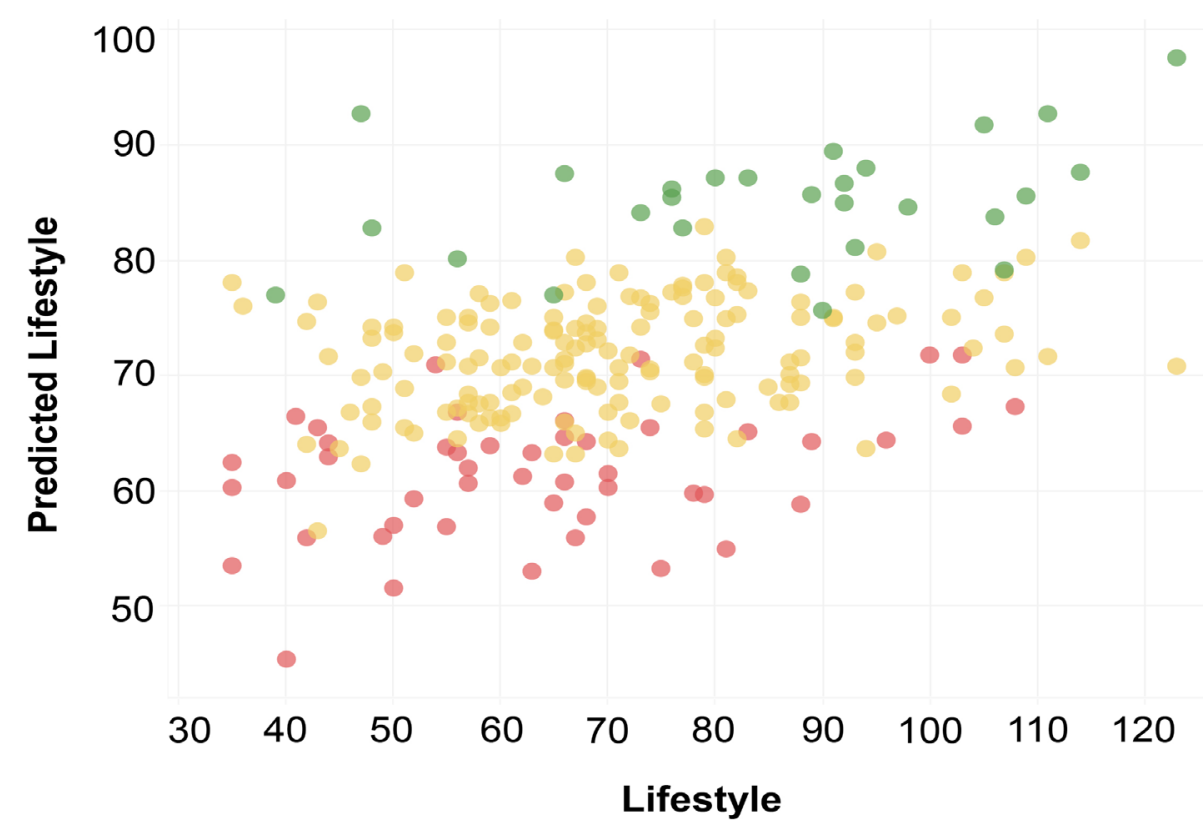

Figure 4. Predicted Lifestyle versus Lifestyle for general linear model (3) shaded by Grit (green: Grit $<3$, yellow: $3<$ $=$ Grit $<4$, red: Grit $>=4), r^{2}=.18, p<0.0001$.

\section{Grit and MEQ}

Both Grit and MEQ were significant predictors of steps and lifestyle, with grit a better predictor of lifestyle $(\beta=$ 13.712, $r=0.39, p<0.0001)$ and MEQ a better predictor of Steps $(\beta=66.48, r=0.19, p=0.0001)$. Grit and MEQ are also correlated with each other $(r=.25, p<.0001)$ indicating that, in general, the more of a morning person the students is, the higher their grit score (Grit $=2.69+0.018 * \mathrm{MEQ})$, see Figure 5. Interestingly, neither sex nor age was significant when controlled for in a more general linear model, $p>.4$ for all combinations. 


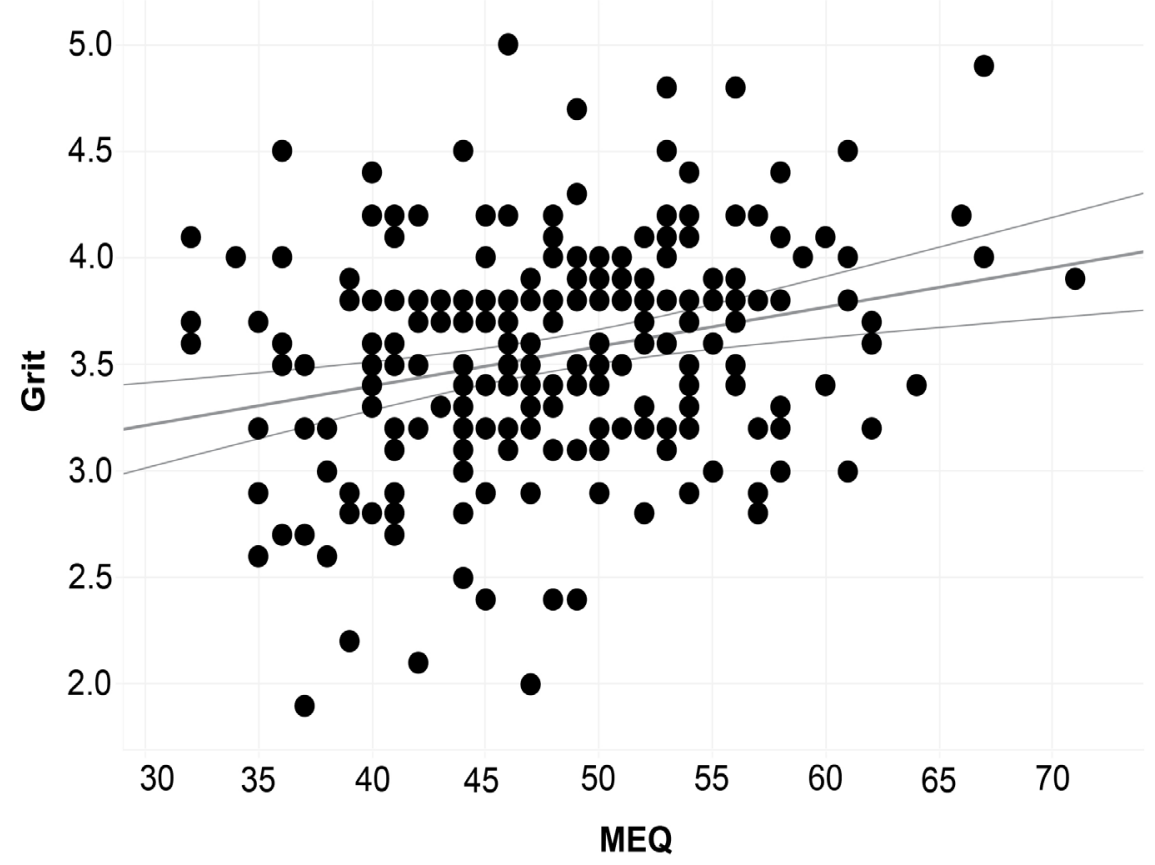

Figure 5. Grit vs. MEQ $(\beta=0.018, \mathrm{r}$-squared $=0.25, \mathrm{p}<0.0001)$.

\section{DISCUSSION}

The study aim was to quantify the relationship between grit, chronotype, physical activity, and leading a healthy lifestyle in college-age students. We collected physical activity data (steps per day) using Fitbits, and measures of grit, chronotype, and healthy lifestyle using standard instruments from 431 first-semester freshmen students (262 females, 169 males) during the 2019 fall semester.

The study results were consistent with previous studies showing that chronotype (MEQ) was negatively correlated with lifestyle score $(\beta=-.618, p<.001)$, i.e., night owls live less healthy lifestyles than their lark counterparts (Schaal et al., 2011; Urbán et al., 2011; Haraszti et al., 2014; Maukonen et al., 2016; Mota et al., 2016). We also found that lifestyle score was negatively correlated with sex $(\beta=-3.992, p=.0357)$, with men leading healthier lifestyles. While surprising, this result was also in agreement with previous studies (Olfert et al., 2019).

Previous studies found that grit was associated with general well-being (Salles et al., 2014; Datu et al., 2016; Kleiman et al., 2013; Hill et al., 2016; Musumari et al., 2018), but little research had been conducted to investigate the link between grit and lifestyle. Our results showed that grit was negatively and directly correlated with lifestyle score $(\beta=-13.712, p<.001)$, i.e., students with higher levels of grit led significantly healthier lifestyles. In fact, we found that grit was a more significant predictor of healthy lifestyle than MEQ.

Similarly, our results showed that both chronotype (MEQ, $p<.0001)$ and grit $(p=.0496)$ were significant predictors of physical activity (steps), even when we controlled for both sex and age. This finding is consistent with previous studies that have shown morning chronotypes as more physically active than their evening counterparts (Schaal et al., 2011; Urbán et al., 2011; Kauderer \& Randler, 2013; Haraszti et al., 2014; Maukonen et al., 2016; Mota et al., 2016). However, when we include both Grit and MEQ in the same model, only MEQ remained significant, regardless of whether Sex and Age are controlled for. This result combined with a close examination of the individual correlation statistics suggests that Grit is less strongly correlated with physical activity when compared with MEQ. 
The findings of this study showed that both grit and chronotype were significantly correlated with physical activity and living a healthy lifestyle, with grit being a better predictor of lifestyle $(\beta=-13.712, r=.39, p<.0001)$ and MEQ a better predictor of steps $(\beta=66.48, r=.19, p=.0001)$. Grit and MEQ are also correlated $(r=.25, p<.0001)$, indicating that grit scores increase as morning activity preferences increase.

\section{LIMITATIONS}

The study was limited in sample size $(N=431)$. While not too small for significant statistical results, other results, especially in sex differences, may have been significant with a larger sample (no power analysis was done). The study was also limited in method, i.e., being a cohort-type observational study rather than a randomized controlled trial.

\section{CONCLUSION}

This study found that grit, chronotype, steps, and lifestyle have strong interrelationships, with grit being a better predictor of a healthy lifestyle and chronotype being a better predictor of physical activity. We also found that chronotype was a significant predictor of grit, with morning types being grittier. Our study extends the understanding of the positive effects of a whole-person approach to education with concrete implications for both campus policymakers and educators alike. Developing grit, improving sleep hygiene, and providing incentives for students to lead a healthy and physically active lifestyle will assist in the development of healthy academic communities. 


\section{REFERENCES}

Broaddus, A. M., Jaquis, B. J., Jones, C. B., Jost, S. R., Lang, A. S. I. D., Li, A., ... \& Spear, E. M. (2019). Fitbits, field-tests, and grades: The effects of a healthy and physically active lifestyle on the academic performance of first year college students. International Journal of Sport and Exercise Psychology, 1-12. https://doi.org/10.1080/1612197X.2019.1623062

Bullock, B. (2019). An interdisciplinary perspective on the association between chronotype and well-being. The Yale Journal of Biology and Medicine, 92(2), 359-364. Retrieved from https://www.ncbi.nlm.nih.gov/pmc/articles/PMC6585516/

Centers for Disease Control and Prevention. (2020). Physical activity: Benefits of physical activity. Retrieved from https://www.cdc.gov/physicalactivity/basics/pa-health/

Cheng, J.-S., Yang, M.-C., Ting, P.-H., Chen, W.-L., \& Huang, Y.-Y. (2011). Leisure, lifestyle, and health-related physical fitness for college students. Social Behavior and Personality: An International Journal, 39(3), 321-332. https://doi.org/10.2224/sbp.2011.39.3.321

Credé, M., Tynan, M. C., \& Harms, P. D. (2017). Much ado about grit: A meta-analytic synthesis of the grit literature. Journal of Personality and Social Psychology, 113(3): 492-511. https://doi.org/10.1037/pspp0000102

Datu, J. A. D., Valdez, J. P. M., \& King, R. B. (2016). The successful life of gritty students: Grit leads to optimal educational and well-being outcomes in a collectivist context. In R. B. King \& A. B. I. Bernardo (Eds.), The psychology of Asian learners: A Festschrift in honor of David Watkins (pp. 503-516). Singapore: Springer Singapore. https://doi.org/10.1007/978-981-287-576-1_31

Dickinson, D. L., Wolkow, A. P., Rajaratnam, S. M. W., \& Drummond, S. P. A. (2018). Personal sleep debt and daytime sleepiness mediate the relationship between sleep and mental health outcomes in young adults. Depression \& Anxiety (1091-4269), 35(8), 775-783. https://doi.org/10.1002/da.22769

Duckworth, A. L., Peterson, C., Matthews, M. D., \& Kelly, D. R. (2007). Grit: Perseverance and passion for longterm goals. Journal of Personality and Social Psychology, 92(6), 1087-1101. https://doi.org/10.1037/00223514.92.6.1087

Fischer, D., Lombardi, D. A., Marucci-Wellman, H., \& Roenneberg, T. (2017). Chronotypes in the US - influence of age and sex. PLOS ONE, 12(6), e0178782. https://doi.org/10.1371/journal.pone.0178782

Ferguson, C., Kaneta, L., Li, A., Nelson, P., Satralkar, M., \& Lang, A. S. I. D. (2018). Chronotype as a predictor of academic success of university freshmen. International Journal of Psychology and Neuroscience, 4(2), 37-48. Retrieved from https://works.bepress.com/andrew-sid-lang/33/

Goldin, A. P., Sigman, M., Braier, G., Golombek, D. A., \& Leone, M. J. (2020). Interplay of chronotype and school timing predicts school performance. Nature Human Behaviour, 4(4), 387-396. https://doi.org/10.1038/s41562-020-0820-2

Haraszti, R. Á, Purebl, G., Salavecz, G., Poole, L., Dockray, S., \& Steptoe, A., (2014). Morningness-eveningness interferes with perceived health, physical activity, diet and stress levels in working women: A cross-sectional study. Chronobiology International, 31(7), 829-837. https://doi.org/10.3109/07420528.2014.911188 
Hill, P. L., Burrow, A. L., \& Bronk, K. C. (2016). Persevering with positivity and purpose: An examination of purpose commitment and positive affect as predictors of grit. Journal of Happiness Studies. 17(1), 257-269. https://doi.org/10.1007/s10902-014-9593-5

Horne J. A., Östberg O. (1976). A self-assessment questionnaire to determine morningness-eveningness in human circadian rhythms. International Journal of Chronobiology, 4(2), 97-110. PMID: 1027738

Huber, F. (2016). Essentials of physical activity. Peosta, IA: Eddie Bowers.

Kauderer, S., \& Randler, C. (2013). Differences in time use among chronotypes in adolescents. Biological Rhythm Research, 44(4), 601-608. https://doi.org/10.1080/09291016.2012.721687

Kleiman, E. M., Adams, L. M., Kashdan, T. B., \& Riskind, J. H. (2013). Gratitude and grit indirectly reduce risk of suicidal ideations by enhancing meaning in life: Evidence for a mediated moderation model. Journal of Research in Personality, 47(5), 539-546. https://doi.org/10.1016/j.jrp.2013.04.007

Kroger, J. (2005). Chapter ten: Identity development during adolescence. Blackwell handbook of adolescence, (pp. 205226). John Wiley \& Sons, Inc. https://doi.org/10.1002/9780470756607.ch10

Lang, A. S. I. D., Allee, M., Anderson, S., Bloom, M., Jost, S., Keating, D., ... \& Valderrama, E. (2020). Dataset: The Influence of Chronotype and Grit on Lifestyle and Physical Activity (Version 1). figshare. [Dataset]. https://doi.org/10.6084/m9.figshare.12103617.v1

Maukonen, M., Kanerva, N., Partonen, T., Kronholm, E., Konttinen, H., Wennman, H., \& Männistö, S. (2016) The associations between chronotype, a healthy diet and obesity. Chronobiology International, 33(8), 972-981. https://doi.org/10.1080/07420528.2016.1183022

McMahon, D. M., Burch, J. B., Youngstedt, S. D., Wirth, M. D., Hardin, J. W., Hurley, T. G., ... \& Hebert, J. R. (2019). Relationships between chronotype, social jetlag, sleep, obesity and blood pressure in healthy young adults. Chronobiology International, 36(4), 493-509. https://doi.org/10.1080/07420528.2018.1563094

Mota, M. C., Waterhouse, J., De-Souza, D. A., Rossato, L. T., Silva, C. M., Araújo, M. B. J., ... \& Crispim, C. A., (2016). Association between chronotype, food intake and physical activity in medical residents. Chronobiology International, 33(6), 730-739. https://doi.org/10.3109/07420528.2016.1167711

Musumari, P. M., Tangmunkongvorakul, A., Srithanaviboonchai, K., Techasrivichien, T., Suguimoto, S. P., OnoKihara, M., \& Kihara, M. (2018). Grit is associated with lower level of depression and anxiety among university students in Chiang Mai, Thailand: A cross-sectional study. PLOS ONE, 13(12), e0209121. https://doi.org/10.1371/journal.pone.0209121

Norbury, R., \& Evans, S. (2019). Time to think: Subjective sleep quality, trait anxiety and university start time. Psychiatry Research, 271, 214-219. https://doi.org/10.1016/j.psychres.2018.11.054

Olfert, M. D., Barr, M. L., Charlier, C. C., Greene, G. W., Zhou, W., \& Colby, S. E. (2019). Sex differences in lifestyle behaviors among U.S. college freshmen. International Journal of Environmental Research and Public Health, 16(3), 482. https://doi.org/10.3390/ijerph16030482

Oral Roberts University. (2017). GEN 150 - Introduction to whole person education, 1 Credit hour [Syllabus]. Tulsa, OK: ORU. Retrieved from https://syllabi.oru.edu/?id=48815 
Park, H., Lee, H.-K., \& Lee, K. (2018). Chronotype and suicide: The mediating effect of depressive symptoms. Psychiatry Research, 269, 316-320. https://doi.org/10.1016/j.psychres.2018.08.046

Pedrelli, P., Nyer, M., Yeung, A., Zulauf, C., \& Wilens, T. (2015). College students: mental health problems and treatment considerations. Academic Psychiatry, 39(5), 503-511. https://doi.org/10.1007/s40596-014-0205-9

R Core Team (2019). R: A language and environment for statistical computing. R Foundation for Statistical Computing, Vienna, Austria. Retrieved from https://www.R-project.org/

Romo-Nava, F., Tafoya, S. A., Gutiérrez-Soriano, J., Osorio, Y., Carriedo, P., Ocampo, B., ... \& Heinze, G. (2016). The association between chronotype and perceived academic stress to depression in medical students. Chronobiology International, 33(10), 1359-1368. https://doi.org/10.1080/07420528.2016.1217230

Sack, R. L., Auckley, D., Auger, R. R., Carskadon, M. A., Wright Jr, K. P., Vitiello, M. V., \& Zhdanova, I. V. (2007). Circadian rhythm sleep disorders: part I, basic principles, shift work and jet lag disorders. Sleep, 30(11), 14601483. https://doi.org/10.1093/sleep/30.11.1460

Salles, A., Cohen, G. L., \& Mueller, C. M. (2014). The relationship between grit and resident well-being. The American Journal of Surgery, 207(2), 251-254. https://doi.org/10.1016/j.amjsurg.2013.09.006

Saunders-Scott, D., Braley, M. B., \& Stennes-Spidahl, N. (2018). Traditional and psychological factors associated with academic success: Investigating best predictors of college retention. Motivation \& Emotion, 42(4), 459465. https://doi.org/10.1007/s11031-017-9660-4

Schaal, S., Peter, M., \& Randler, C. (2011). Morningness-eveningness and physical activity in adolescents. International Journal of Sport \& Exercise Psychology, 8(2), 147-159. https://doi.org/10.1080/1612197X.2010.9671939

Suh, S., Yang, H.-C., Kim, N., Yu, J. H., Choi, S., Yun, C.-H., \& Shin, C. (2017). Chronotype differences in health behaviors and health-related quality of life: A population-based study among aged and older adults. Behavioral Sleep Medicine, 15(5), 361-376. https:/ / doi.org/10.1080/15402002.2016.1141768

Tudor-Locke, C., \& Aguiar, E. J. (2018). Toward comprehensive step-based physical activity guidelines: Are we ready? Kinesiology Review, 8(1), 25-31. https://doi.org/10.1123/kr.2018-0065

Türkmen, M., Kul, M., Ocalan, M., Özkan, A., \& Bozkus, T. (2013). Determination of the relationship between physical activity levels and healthy lifestyle behaviors of university students. Australian Journal of Basic and Applied Sciences, 7(10), 507-512. Retrieved from http://www.ajbasweb.com/old/ajbas/2013/August/507512.pdf

Urbán, R., Magyaródi, T., \& Rigó, A. (2011). Morningness-eveningness, chronotypes and health-impairing behaviors in adolescents, Chronobiology International, 28(3), 238-247. https://doi.org/10.3109/07420528.2010.549599

Velten, J., Lavallee, K. L., Scholten, S., Meyer, A. H., Zhang, X. C., Schneider, S., \& Margraf, J. (2014). Lifestyle choices and mental health: A representative population survey. BMC Psychology, 2(1).

https://doi.org/10.1186/s40359-014-0055-y

Vera, B., Dashti, H. S., Gómez-Abellán, P., Hernández-Martínez, A. M., Esteban, A., Scheer, F., ... \& Garaulet, M. (2018). Modifiable lifestyle behaviors, but not a genetic risk score, associate with metabolic syndrome in evening chronotypes. Scientific Reports, 8(1). https://doi.org/10.1038/s41598-017-18268-z 
Warburton, D. E. R., \& Bredin, S. S. D. (2017). Health benefits of physical activity: A systematic review of current systematics reviews. Current Opinion in Cardiology, 32(5), 541-556.

https://doi.org/10.1097/HCO.0000000000000437

Weisskirch, R. S. (2019). Grit applied within: Identity and well-being. Identity, 19(2), 98-108. https://doi.org/10.1080/15283488.2019.1604345

World Health Organization. (2020). Physical Activity and Adults. Retrieved from https://www.who.int/dietphysicalactivity/factsheet_adults/en/

Yuenyongchaiwat, K. (2016). Effects of 10,000 steps a day on physical and mental health in overweight participants in a community setting: A preliminary study. Brazilian Journal of Physical Therapy, 20(4), 367-373. https://doi.org/10.1590/bjpt-rbf.2014.0160

Address author correspondence to:

Andrew S.I.D. Lang, PhD

Senior Professor

Oral Roberts University

Department of Computing \& Mathematics

7777 S. Lewis Ave.

Tulsa, OK 74171

alang@oru.edu

\section{Author's Note and Acknowledgements}

The authors would like to thank the GEN 150 - Introduction to Whole Person Education students who participated in the research study. Additionally, the authors would like to thank Jon Anderson, ORU IT, for his role in porting the Fitbit activity data from Fitbit services into our course management system and Lee Tarrant, ORU Institutional Research, for aggregating, de-identifying, and securing the data for us to analyse. We would also like to recognize and thank the Health, Leisure and Sport Science faculty who teach Introduction to Whole Person Education for their dedication to building a healthy academic community. 